\title{
Crystalline Lens Staining with Intracameral Phenylephrine During Cataract Surgery
}

\author{
Michael Tsatsos, MD, PhD, FRCOphth ${ }^{1,2}$; loannis Athanasiadis, MD, MRCSEd(Ophth) ${ }^{2}$; Corrado Gizzi, MD, PhD ${ }^{2}$ \\ Balal Shafi, MD²; Marilita Moschos, MD, PhD'; Anant Sharma, MD, FRCOphth ${ }^{2}$ \\ ${ }^{1}$ Aristotelian University of Thessaloniki, Thessaloniki, Greece \\ ${ }^{2}$ Moorfields Eye Hospital, London, United Kingdom \\ ORCID: \\ Michael Tsatsos: https://orcid.org/0000-0003-1280-4113 \\ loannis Athanasiadis: https://orcid.org/0000-0002-6236-7540
}

J Ophthalmic Vis Res 2021; 16 (1): 135-136

\section{PRESENTATION}

During intracameral use of low concentration phenylephrine in several consecutive routine phacoemulsification cases, we have consistently observed a "spikes" pattern of staining in the crystalline lens structures; however, it was not entirely clear whether this involved just the capsule, the cortex, or both (Figure 1). Although it appears that the staining occurs largely at the level of the anterior capsule, some very faint staining could possibly be seen on the anterior lenticular surface as well. The formulation of intracameral phenylephrine (Minims $^{\circledR} \quad$ Phenylephrine Hydrochloride, Bausch \& Lomb UK Ltd.) that is routinely used in our practice consists of $0.5 \mathrm{ml}$ of $10 \%$ phenylephrine preservative free minims mixed with $0.5 \mathrm{ml}$ of $2 \%$ lidocaine and $1 \mathrm{ml}$ of Balanced Salt Solution with adrenaline. This mixture $(0.2 \mathrm{ml})$ was injected in the anterior chamber.

\section{Correspondence to:}

Ioannis Athanasiadis, MD, MRCSEd(Ophth). Moorfields Eye Hospital at Bedford Eye Clinic, Kempston Road, Bedford, MK42 9DJ, United Kingdom.

E-mail: athana1972@yahoo.com

Received: 18-06-2018Ａccepted: 21-03-2020

\section{Access this article online}

Website:

https://knepublishing.com/index.php/JOVR

DOI:

10.18502/jovr.v16i1.8261

\section{DISCUSSION}

Phenylephrine is an $\alpha$-adrenergic agonist regularly used as a dilating agent in the form of eye drops prior to intraocular surgery such as cataract surgery. It is also frequently used as an intracameral injection in conditions such as floppy iris syndrome to assist with pupillary dilation as well as to increase the iris tone. ${ }^{[1,2]}$

No evidence of capsular staining was observed in our patients at postoperative visits. There were no reported or observed cases of toxic anterior segment syndrome or other systemic or vision-threatening complications intraoperatively or during the postoperative period. Although Lockington et al reported the possibility of toxicity associated with the presence of free radicals in intracameral phenylephrine formulations, we report no relevant deviations from routine practice in our patients. ${ }^{[3]}$

Lens staining was consistent in all cases where the intracameral phenylephrine formulation was used. It began to appear in $20 \mathrm{sec}$, peaking at around $1 \mathrm{~min}$ after the intracameral injection (Figure 2). We believe that the resulting appearance of the crystalline lens can facilitate capsulorrhexis in routine as well as in cases of borderline visibility

This is an open access journal, and articles are distributed under the terms of the Creative Commons Attribution-NonCommercial-ShareAlike 4.0 License, which allows others to remix, tweak, and build upon the work non-commercially, as long as appropriate credit is given and the new creations are licensed under the identical terms.

How to cite this article: Tsatsos M, Athanasiadis I, Gizzi C, Shafi B, Moschos $M$, Sharma A. Crystalline Lens Staining with Intracameral Phenylephrine During Cataract Surgery. J Ophthalmic Vis Res 2021;16:135-135. 


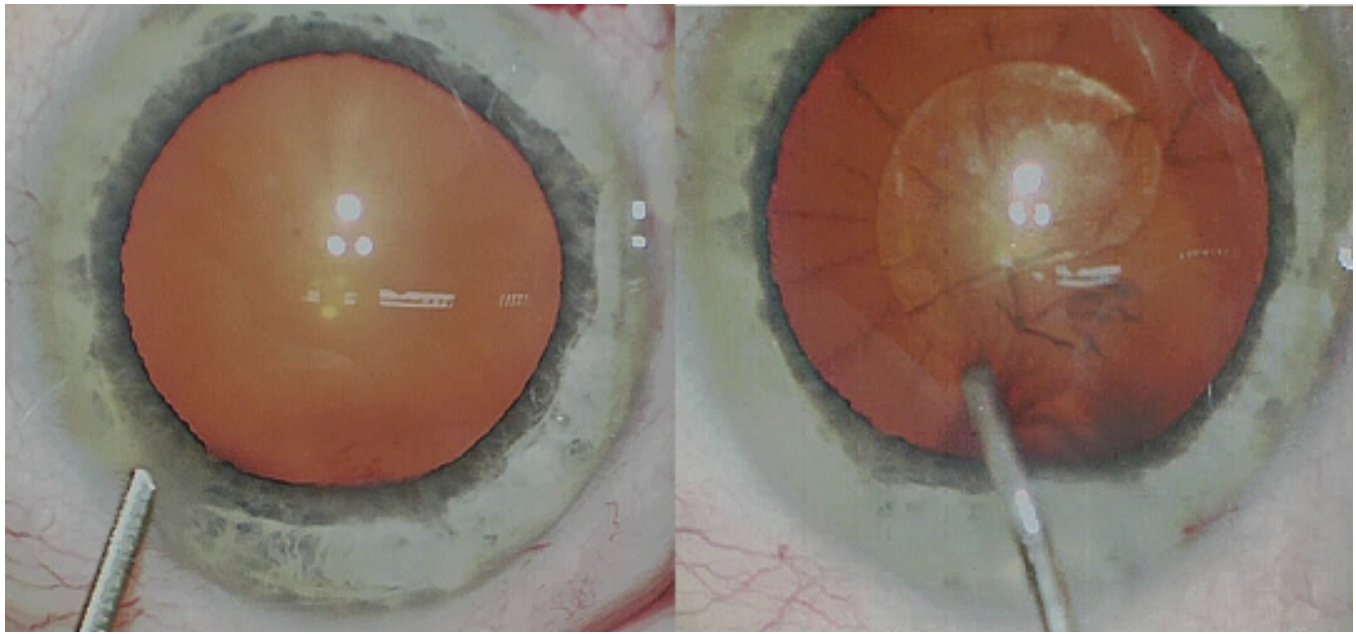

Figure 1. Spike-like staining of the crystalline lens (arrows) following intracameral injection of phenylephrine hydrochloride.
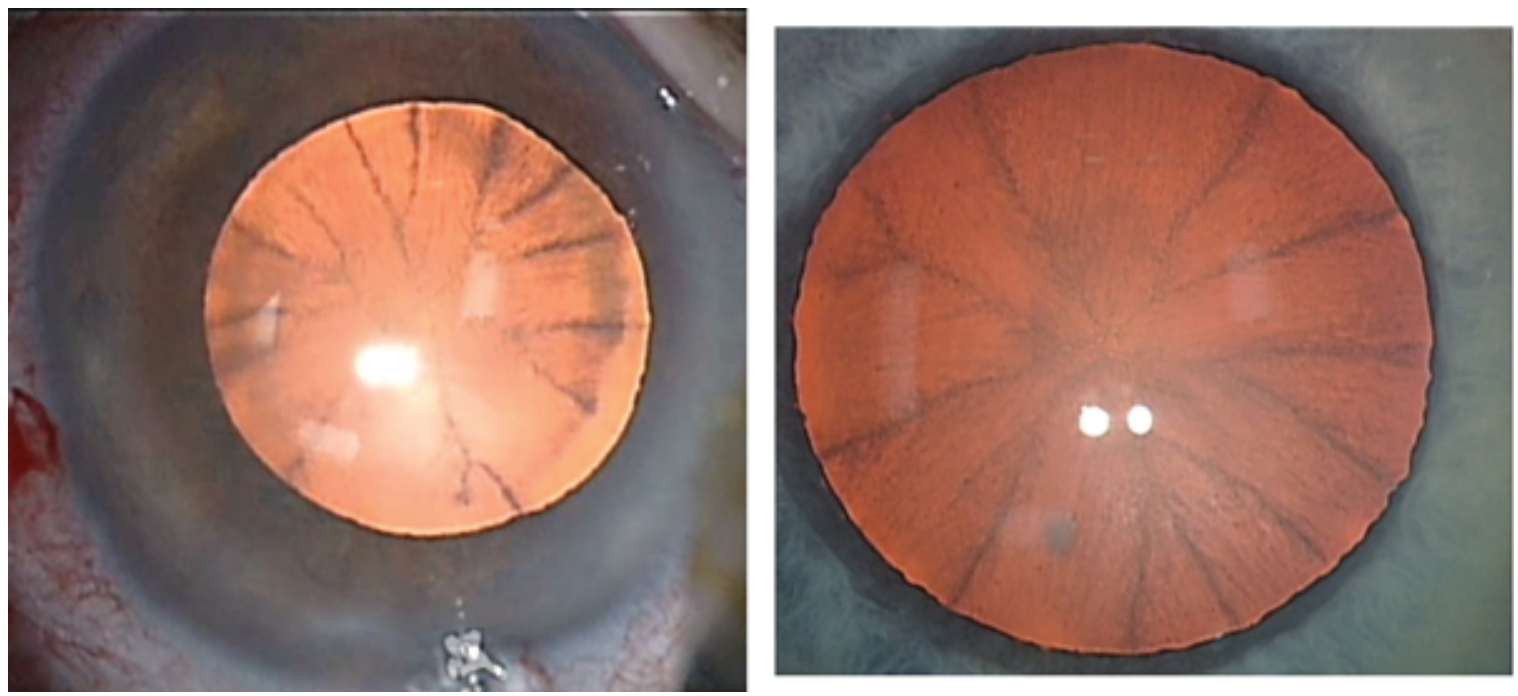

Figure 2. Early (left) and late (right) staining of the crystalline lens following intracameral use of phenylephrine hydrochloride in two different patients.

where usually a staining agent such as trypan blue is considered by the surgeon. Thus, no extra provisions need to be made resulting in reduced cost of surgery as well as less logistical burden on the operation theatre.

Furthering our understanding on the cause of crystalline lens staining related to intracameral phenylephrine and its implications will hopefully enable us to use this agent more effectively as a mydriatic and to facilitate capsulorrhexis in routine as well as complicated cases.

\section{Financial Support and Sponsorship}

Nil.

\section{Conflicts of Interest}

There are no conflicts of interest.

\section{REFERENCES}

1. Lundberg B, Behndig A. Intracameral mydriatics in phacoemulsification cataract surgery. J Cataract Refract Surg 2003;29:2366-2371.

2. Lorente R, de Rojas V, Vázquez de Parga P, Moreno C, Varela J, et al. Intracameral phenylephrine $1.5 \%$ for prophylaxis against intraoperative floppy iris syndrome: prospective, randomized fellow eye study. Ophthalmology 2012;119:2053-2058.

3. Lockington D, Macdonald EC, Young D, Stewart P, Caslake $\mathrm{M}$, Ramaesh K. Presence of free radicals in intracameral agents commonly used during cataract surgery. $\mathrm{Br} \mathrm{J}$ Ophthalmol 2010;94:1674-1677. 